\title{
Key Stakeholders' Perceptions Regarding Role of Mentors in Primary Schools
}

\author{
* Dr. Farrukh Munir, Lecturer \\ ** Dr. Misbah Akhtar, Assistant Professor \\ *** Syeda Tehmina Naz Bukhari, Assistant Professor
}

\begin{abstract}
The paper aimed to examine part of mentors in the primary schools under the eyes of key stakeholders, the teachers of primary schools (TPSs). This study was carried out in one major district of the Punjab Province. The mixed-methods approach was used to meet the objectives of the study. The population of the research work was all TPSs in the district under study. The study sample was comprised of 1127 TPSs selected through random sampling in layers. Quantitative data was collected on a self-developed structured questionnaire while qualitative data was taken through semi-structured interview protocols from the 32 participants by convenient sampling. Descriptive statistics was employed for analyzing the data through qualitative analytical techniques for the explanation of qualitative data. The results of this research work explored most of the mentoring services of the District teacher educators' were unsatisfactory. The authoritative behavior, less attention towards instructing, and lack of confidence were the key issues of coaching and mentoring. The results of this research work can be supportive in improving the current practices of the mentors for better results of the CPD framework.
\end{abstract}

Keywords: CPD, Mentors, Teachers, Primary Schools

Introduction

Pakistan has been striving hard for years to improve the excellence of school instruction, but the desires are still far away (Munir \& Amin, 2018). In the light of national education policies, each province has implemented several education reforms where great attention has been paid to improving the quality of teachers (Anwar, 2014; Shaukat \& Chowdhury, 2020). Accordingly, in 2006, the Directorate of Staff Development (DSD), Lahore, launched a comprehensive program for teacher professional development (TPD) called the Continuous Professional Development (CPD) Framework of DSD, Lahore (DSD, 2015). DSD used a cascading approach first for the training of mentors as master trainers and then mentoring to meet its initial goals of developing the professional skills of a large number of teachers of primary schools (TPSs). School-based mentoring for TPD is high appraised these days (Murtagh, \& Dawes, 2020). District teacher educators (DTEs) have been given key roles and responsibilities in improving the professional skills of TPSs by the execution of various CPD activities at respective CTSC and attached schools (DSD, 2007a; Munir \& Amin, 2018; Shehzad, 2014). DTEs should visit all schools attached to a given CTSC every month for assessment of the teaching quality and students' performance. He carefully identifies the weak areas of every teacher and tries to improve them through coaching and mentoring at the spot, and then plans for further training at CTSC (Saqib et al., 2020; Saeed, \& Akhtar, 2017). In addition to the duties of continuous mentoring and development, DTEs also evaluate classroom practice and student learning improvement by conducting monthly tests (Munir \& Amin, 2018; Swaminathan, \& Reed, 2020). They determine the training needs of teachers and organize capacity-building sessions to improve such weak areas in collaboration with DSD, Lahore. They encourage teachers to actively participate in all CPD activities carried out by the schools and CTSCs (Shehzad, 2014). The overall goal of CPD is to ensure the presence of well-trained, competent, and professionally sound teachers in all schools,

* Institute of Education and Research, University of the Punjab, Lahore Pakistan

Email: farrukh.ier@pu.edu.pk

** Department of Educational Training. The Islamia University of Bahawalpur, Pakistan, Bahawalnagar Campus Email: misbah.akhtar@iub.edu.pk

*** Department of Education, the Islamia University of Bahawalpur, Pakistan Email: tehminabukhari552@gmail.com 
leading to high-quality education and students' improvement (Shanks et al., 2020). Based on the findings of his assessments, a DTE should have to take the best remedial measures for improvement of teaching-learning quality at the schools (Anwar, 2014; Munir \& Amin, 2018). The main areas of mentoring recognized by DSD, Lahore are teacher record, educational schedule, class planning, instruction and knowledge gaining based on activities, employment of audio-visual supports, learners' interface, class monitoring, learners' evaluation, and assignments (Munir \& Amin, 2018).

The triumph of all mentoring-based CPD much depends on the promise, honesty, undertaking, and commitment of all stakeholders, especially mentees and mentors (Milton et al, 2020). The mentors (DTEs) under the CPD framework of DSD gets all type of guidance and support from the technical team of DSD and also from the "coaching guide" and mentor's guide book regularly (Shehzad, 2014). The DTE makes their work plan considering the instruction laid in these guide books and directions of DSD, technical team. Every DTE must follow the instructions and submit a report of his activities at the end of each month. DSD experts carefully review all reports and provide feedback for improvement as needed (DSD, 2015; Heslop, Burns, \& Lobo, 2020). CPD framework of DSD, Lahore has claimed much improvement in all aspects of the teaching quality but there is much criticism from the various segments of the society on this claim. So there is a need to assess the various aspects of the CPD framework for necessary improvements. Accordingly, this study focused on exploring the situation of the mentoring practices carried out in the public primary schools under the CPD-framework of DSD, Lahore. The key objectives of the study were as follows:

1. To examine the mentor's roles and mentoring practices under the CPD Framework of DSD, Lahore.

2. To explore gaps and problems faced by the mentors and teachers (mentees) in the execution of mentoring activities under the CPD framework.

In the light of the objectives of the study following research questions were developed to investigate the problem.

\section{Research Questions}

Q.1. what are the perceptions of Key stakeholders (teachers) about the mentoring practices in primary schools under the Continuous Professional Development (CPD) Framework?

Q.2. what are the positive and negative aspects of mentoring at primary schools under the eyes of key stakeholders?

\section{Literature Review}

Today, teachers are expected to be competent to engage students from diverse backgrounds to apply new educational techniques, maintain good standards of education, and improve student learning outcomes (Galvão, Marques, Ferreira, \& Braga, 2020). Investing in TPD is seen as the best way to improve the quality of education (Coyne-Foresi \& Nowicki, 2020). Thus, all countries are introducing educational reforms, with particular emphasis on the professional development of teachers in CPD mode in recent years (Munir \& Amin, 2018; Cook, 2020). For teachers, one of the key objectives of CPD is to provide technical support and help throughout their careers (Anwar, 2014; Boukis \& Christodoulides, 2020). Depending on the goals and the organizational context, the CPD program can be developed and implemented in several ways (Munir \& Amin, 2018). The success of any CPD program is based on the selection of the appropriate model after careful needs assessment (Yoon, 2017). Key limiting factors for the CPD program include school environment, school timings, culture, financial constraints, and hope for career success (Appel, Tillinghast, Winsor, \& Mansouri, 2020).

Mentoring model of CPD refers to guide and support both senior and novice teachers in improving their professional skills (Anwar, 2014). Proper mentoring can also aid to retain new teachers for a longer time. During the process of mentoring and coaching, mentors make observations of the classroom practices and note gaps and try to make improvements through mutual discussions. Although mentoring is an easy and cost-effective method of TPD, its success is highly dependent on the competence of mentors (Abdullah, 2020).

Mentoring is a reasonably new-fangled notion in the sector of TPD. Formal and informal types of mentoring are being practiced in various educational institutions in Pakistan. CPD-framework of DSD, Lahore is a novel mode of TPD where the mentoring and guiding approach is applied to improve all categories of school teachers across the province. Munir and Amin (2018) argued that mentoring and guiding model of CPD provides a very successful, valuable, and significant forum for acquiring technical knowledge and professional skills in education. The key aims of the teacher' 
mentoring through CPD are to make certain the presence of sound, skilled, and talented, teachers in the schools to meet the aim of excellent schooling and SLOs (Iqbal, Akhlaq \& Chishti, 2016).

In Punjab, the job of improving the quality of education and standards of teachers was entrusted to the DSD, Lahore in 2004. DSD, Lahore launched the CPD framework in 2006 to develop teachers 'professional skills. DSD implemented the CPD program by cascade and mentoring strategy. For this purpose, the DTEs were given mentoring role for improving teachers' quality. The DTE may perform as a teacher, educator, instructor, and mentor within the framework of CPD (DSD, 2015). The school-based mentoring and coaching model of teacher CPD has gained more consideration in several republics and is a crucial element of Teacher Professional Development across the globe (Anwer, 2014; Shehzad, 2014). Despite a fact that the CPD framework has been implemented, with continuous observing and continuation backing at entire stages, mentoring and coaching skills of the DTEs continue to be probed and carped at various stages. The situation calls for a comprehensive evaluation of the CPD framework and all of its activities related to the improvement of the quality of teachers and education. Consequently, the research work was aimed to assess the mentors' (DTEs) practices in the context of CPD-framework.

\section{Significance of the Study}

The results of research work are expected to offer new working conditions for educators. The study will also support policymakers and education authorities in recognizing the state of teachers' professional development strategies and taking further remedial action in this regard.

Both mentors and TPS (mentees) can get help from the findings of the study for minimizing the negative aspects of mentoring and improving their professional capabilities. The study provides evidence-based knowledge that can be used as baseline information for future researchers in the field of mentoring and teacher CPD.

\section{Methodology}

This study followed the mixed-methods approach to meet the answers to research questions. This approach involves a combination of both quantitative and qualitative methods. The study population consisted of all TPSs belonging to the Faisalabad district. The study sample consisted of 1127 subjects randomly selected from boys' and girls' government primary schools separately. Quantitative data were collected using a self-developed, structured questionnaire (with Urdu translation), The various statements of response (SoR) were added in the structured questionnaire considering the DTEs' guidebook and other published material of DSD, Lahore about the CPD-Framework as well as a guide of the relevant experts. Accordingly, a total of thirty-one (31) SoR was included in the measuring instrument. with a breakup: Teacher's Diary (TD) 2-SoR; Homework (HW) 1SoR; Academic-calendar (AC) 3-SoR; Activity Based Teaching (ABT) 1-SoR; AV-Aids 2SoR; Students' Assessment (SA) 2-SoR; Lesson Planning (LP) 2-SoR; Interaction with Students (IwS) 4-SoR; Classroom Management (CM) 3-SoR; Teachers' Training (4-SoR), Performance of Teachers (4-SoR), School Visits (1-SoR), Mentors' Behavior (1-SoR). TPSs were requested to give their views based on interaction with the DTEs on 6 points Likert Scale (0-never practices to 6always practices) against each SoR. For a deeper understanding of the findings of quantitative data analysis, detailed views of the purposively selected TPSs (32-No) were taken, using semi-structured interview protocols.

\section{Analysis}

Descriptive statistics were used to analyze the data of responses of the TPS. The reply choices were always, many times, sometimes, rarely, very rarely, and never on a six-point Likert scale. These response options are always $=5(100 \%)$, many times $=4(76-99 \%)$, sometimes $=3(51-75 \%)$, rarely $=$ $2(26-50 \%)$, very rarely $=1(01-25 \%))$ and never $=0(0 \%)$. Mean values of response (MVR) were calculated to evaluate DTE performances. Ranges were defined to interpret the MVRs as: most frequent $(4.5 \leq \mathrm{MVR}<5)$, frequent $(3.5 \leq \mathrm{MVR} \leq 4.5)$, infrequent $(2.5 \leq \mathrm{MVR}<3.5)$, rare $(1.5 \leq$ MVR $<2.5)$, very rare $(0.5 \leq$ MVR $<1.5)$, and never practice $(0.0 \leq$ MVR $<0.5)$. Data from all assessment statements related to DTEs' practices of mentoring were added to Microsoft Excel Sheets and then analyzed through SPSS version 26. Thematic analysis was done to analyze the qualitative data. After familiarization of the data, various themes were developed and responses of the participants were added under the relevant theme and analyzed. 
Interpretation of the Results

A. Perceptions of the TPSs (the key stakeholders) about the role of mentors in Primary Schools (research question-1)

It was observed that the majority of the practices related to the mentoring role of DTEs were not satisfactory and at the infrequent stage. The quantitative data revealed that most practices of mentoring were at the average (frequent) or below average (infrequent or rare) level as perceived by the TPSs (Table 1). Areas wise interpretation of the results of the analysis of opinions of the TPSs is given below:

TD: Consistent with the views of TPSs, it was observed that the practices of the DTEs about the guide and instruction on the preparation of TD were at the below-average level (frequent, MVR = 4.22). Mentors guide teachers to prepare the TD and check the TD $(M V R=4.04)$ frequently.

HW: Although HW is an important aspect of getting SLOs yet the practices of DTEs about this aspect of mentoring were at a below-average level (rare level, MVR $=2.71$ ).

AC: Mentors' practices in the area of Academic Calendar were below average. Active participation in extra-curricular activities help keep students active and healthy with results in easy learning and gaining SLOs but the findings of the study indicated that the DTEs practices about this aspect of mentoring was at a rare level (MVR $=3.02)$ and also to help learners attain SLOs (MVR = 2.80) was a rare practice of mentors (DTEs).

Activity-Based Education: It is a well-known fact that learning improves by engaging students in activity-based learning but unfortunately, mentors' practices about this aspect of mentoring were also at a rare level $(\mathrm{MVR}=3.31)$.

Usage of Audio Visual supporting material: Reflections of the TPS views indicated that mentors' practices about this aspect of mentoring were at average/ frequent level (MVR $=4.11)$. Also the provided help and guide to mentees about making low/no cost material frequently (3.48).

Student Evaluation: MVRs of TPSs' opinions (MVR = 4.25) indicated that mentors (DTEs) frequently help TPSs to evaluate student performance. Also, monthly assessments/tests were also frequently organized by the mentors $(\mathrm{MVR}=4.04)$.

Lesson Plan: The MVRs of the opinion of the TPSs found that support and guide about LP were below average/rare practice (MVR $=3.31$ ) of the mentors.

Interaction with the students: The MVRs of the TPS opinions (MVR $=4.23$ ) exposed guiding teachers to know $(\mathrm{MV}=3.43)$ and support $(\mathrm{MV}=3.02)$ the pupils having difficulties in learning were infrequent practices of the mentors. The mentors did not ensure the provision of equal learning opportunities for these students (MV=2.85) frequently.

Classroom Management $($ CRM): MVRs of TPS opinions $(M V R=4.07)$ found that teachers frequently helped TPSs to comprehend their class glitches. Also, teachers were frequently motivated to create a supportive environment of learning in classrooms (MVR $=3.62$ ). We conclude that mentors frequently guided teachers about CRM.

Teacher training: TPSs MVRs (MVR $=4.04)$ showed that mentors organized teacher and principal meetings monthly to exchange professional experience, often did not consolidate educator training in the light of recognized requirements (MVR $=3,48$ ). Furthermore, recognizing the specialized requirements of educators (MVR $=2.99$ ) and instructive backing for educators during instruction $(\mathrm{MVR}=2.91)$ were also rare practices among teachers.

Evaluation of teacher performance: The MVRs of the TPS opinion found that mentors frequently evaluated teacher performance in the light of defined gauges (MVR $=3.54)$. It was displayed that assisting teachers to accomplish indicators of performance (MVR $=3.02$ ), ranking TPSs per indicators of performance (MVR $=3.02$ ), identify the finest teacher for mentoring ( $M V R=2.84$ ) were at the infrequent level practices of the DTEs.

School visits of mentors: MVRs of the opinion of TPSs found that mentors visited schools most often as planned (MVR $=4.68)$.

Mentors' Behaviour: Mentors' behavior with TPSs is very important in the successful execution of any mentoring program as it results in the creation of confidence and trustworthiness. The findings showed that the mentors' behavior with teachers was not polite and supportive (MVR $=3.22$ ).

Summary

TPSs believe that the majority of mentors' practices were below average (rare stage). From the data, it can be concluded that the mentors' practice of 'guide to preparing TD' was a rare stage. Mentoring 
about doing curriculum activities per plan of action, the use of supporting materials, and assessment of students were frequent practices of the mentors. Practices of DTEs regarding conducting monthly student tests, using teacher guides in the classroom, applying new teaching methods, student participation and student motivation, solving classroom problems, favorable classroom environment, and monthly meetings with TPS to exchange professional experience and assessed performance were found as frequent practices of the DTEs. It was explored that teachers' direction to assigning and checking HW and organizing curriculum activities regularly were also frequent practices of the DTEs.

The data indicated that practices of the mentors to guide and support teachers and to help teachers implement SLO., and motivating teachers for ABT, helping TPSs to make low or no cost material for use in teaching-learning activities were perceived as the infrequent practice of the mentors.

According to TPSs, mentors rarely guide teachers to assess student performance. It is too evident from the data analysis that the attitude of teachers was not supporting and helpful for learners.

Table 1: Mean Values of TPSs' View about Performs of DTEs as Mentor

\begin{tabular}{|c|c|c|c|}
\hline Statement about Practices of DTEs & $\mathbf{N}$ & Mean & SD \\
\hline \multicolumn{4}{|l|}{ TD $(M V R=4.13)$} \\
\hline guide about the preparation of TD & 1127 & 4.22 & 1.04 \\
\hline checks TD regularly & 1127 & 4.04 & 0.89 \\
\hline \multicolumn{4}{|l|}{ Homework $(\mathrm{HW})(\mathrm{MVR}=2.71)$} \\
\hline \multicolumn{4}{|l|}{ Academic Calendar (AC) (MVR=3.19) } \\
\hline organize curricular actions in the light of the educational plan & 1127 & 3.75 & 0.91 \\
\hline organize co-curricular actions in the light of the educational plan & 1127 & 3.02 & 1.03 \\
\hline Assist instructors and leaders to gain SLOs. & 1127 & 2.80 & 0.80 \\
\hline \multicolumn{4}{|l|}{ Activity-Based Teaching $(\mathrm{MVR}=3.31)$} \\
\hline motivate teachers for $\mathrm{ABT}$ & 1127 & 3.31 & 0.80 \\
\hline \multicolumn{4}{|l|}{ Use of AV Aids (MVR=3.80) } \\
\hline direct instructors to apply backing material during instruction & 1127 & 4.11 & 1.15 \\
\hline direct instructors to get ready free material & 1127 & 3.48 & 0.77 \\
\hline \multicolumn{4}{|l|}{ Students Assessment(SA) $(\mathrm{MVR}=4.15)$} \\
\hline guide teachers to assess the student's performance & 1127 & 4.25 & 1.12 \\
\hline ensure the conduct of students' monthly assessment/test & 1127 & 4.04 & 1.04 \\
\hline \multicolumn{4}{|l|}{ Lesson Plan (MVR=3.60) } \\
\hline make sure the usage of teacher guide in the classroom & 1127 & 3.91 & 0.97 \\
\hline $\begin{array}{l}\text { make certain that the teachers apply suitable approaches to teaching in the } \\
\text { classroom }\end{array}$ & 1127 & 3.50 & 0.87 \\
\hline \multirow{2}{*}{\multicolumn{4}{|c|}{ Interaction with Students (IwS) (MVR=3.38) }} \\
\hline & & & \\
\hline ensure Teacher Guides use in the classroom & 1127 & 4.23 & 1.11 \\
\hline $\begin{array}{l}\text { ensure the use of appropriate teaching methods are used in the } \\
\text { classroom }\end{array}$ & 1127 & 3.43 & 1.07 \\
\hline guide teachers preparing of Lesson Plan & 1127 & 3.02 & 1.00 \\
\hline ensure the use of Teacher Guides in the classroom & 1127 & 2.85 & 1.05 \\
\hline \multicolumn{4}{|l|}{ Classroom Management (MVR=3.80) } \\
\hline Assist instructors to understand their classroom problems during teaching. & 1127 & 4.07 & 1.10 \\
\hline Inspire instructors to spread cooperation to resolve classroom problems. & 1127 & 3.70 & 0.93 \\
\hline Assist instructors to create a classroom environment favorable. & 1127 & 3.62 & 1.10 \\
\hline \multicolumn{4}{|l|}{ Training of Teachers (MVR=3.36) } \\
\hline $\begin{array}{l}\text { establish monthly meetings of instructors and head instructors to discuss } \\
\text { professional experiences at cluster level }\end{array}$ & 1127 & 4.04 & 1.11 \\
\hline establish training of instructors about recognized requirements on PD day & 1127 & 3.48 & 0.79 \\
\hline Find Professional Needs of the Instructors during teaching & 1127 & 2.99 & 1.06 \\
\hline offer instructional support to educators during teaching & 1127 & 2.91 & 0.99 \\
\hline \multicolumn{4}{|l|}{ Teacher's Performance $(M V R=3.11)$} \\
\hline evaluate the performance of the educators according to set pointers & 1127 & 3.54 & 0.94 \\
\hline make the ranking of educators in the light of enactment pointers & 1127 & 3.02 & 0.73 \\
\hline assist instructors to attain enactment pointers & 1127 & 3.02 & 1.16 \\
\hline recognize the effective instructors for the teaching of other educators & 1127 & 2.84 & 1.04 \\
\hline
\end{tabular}


Visit schools per plan

Mentor's Behavior with Teachers $(\mathrm{MVR}=3.22)$

Interact with the teachers, in a pleasant way

\section{7}

1127
4.68

3.22

\subsection{7}

B. Perceptions of the key stakeholders about the positive and negative areas of mentoring (Research question 2)

To triangulate the quantitative data offered above, we conducted semi-structured face-to-face meetings with thirty-two TPSs to look for their recognition of mentoring activities and to see if the qualitative data backing the quantitative findings. Furthermore, TPSs were also asked to talk about the positive and negative areas of mentoring practices under the CPD framework to form an all-inclusive depiction of mentoring activities of the DTEs at primary schools. The replies of the TPSs were scrutinized and the themes were drawn and presented accordingly.

Qualitative data of TPSs' on instructing practices of mentors are presented in Table 2. The finding of data analysis shows that mentors (DTEs) focus to act as a supervisor and administrator rather than a helper and mentor TPSs to develop teaching skills. From the analysis of the qualitative data, it can be concluded that most of the TPSs were conscious of the mentoring duties of the DTEs. The responses of the majority of teachers showed that teachers do not guide them to develop skills of teaching such as preparing a TD, planning an LP and AV aids, activity-based education, student assessment, and IwS, and so on. DTEs were monitoring TPSs' performance as a manager and did not focus on helping and guiding teachers. The qualitative data analysis also displayed that the mentors try to achieve the goals they wanted to report. The mentors did not organize the TPS training in the light of the evidence of assessment that displayed the non-professional attitude of the mentors during the execution of CPD jobs.

The main positive aspects of mentoring and coaching were improving teacher regularity, enrolling students, improving school and classroom discipline, teacher training, some improvement in the use of teacher guides, healthy competition between teachers and schools, AV aids in teaching.

Negative aspects of coaching and mentoring were observed as a result of the thematic analysis of TPSs' views: incredible behavior of mentors, less mentoring and more evaluation, organization of training and capacity building activities without real needs assessment, traditional teaching method, lack of content knowledge, especially in science subjects, lack of self-confidence, mentors' extensive travel due to non-transferable jobs, lots of expectations, and no rewards or promotions for well-performing mentors.

\section{Discussion}

From the above data, it appears that the practices of the mentors (DTEs) do not meet the required targets according to the understandings of the TPSs. From thirteen areas of evaluation, only one practice of the DTEs (the mentor visits schools as planned) was better (most frequent), and the practices of the mentors in the five areas of the evaluation were at the average stage (frequently observed), viz., preparing a diary of teachers, audio-visual support, learners evaluation, planning for lesson and CRM, while mentors' (DTEs) practices about seven aspects of mentoring and coaching of TPSs were at the stage of rare practices, viz. the instructing direction on learner contact in education, teacher training, based education, mentors behavior, adherence to the educational chart, teacher presentation, and HW. The lack of expertise of DTEs to accomplish mentoring tasks properly is the main cause for the poor output of TPSs against CPD activities. The findings of this research work partly agree with the results of Saleem and Ashiq (2020), who highlighted the great need to review the program of teacher mentoring to set goals for the enhanced professional skills of teachers. Abdullah (2020) examined whether the use of teacher diaries, regular assignments, and monitoring of HW and activity-based teaching and maintenance discipline in the classroom has improved. Our study also explored these things as a positive aspect of mentoring, but progress is small. The results of Appel, Tillinghast, Winsor, and Mansouri (2020) revealed challenges facing DTEs that were similar to our results. Similarly, Cook (2020) and Heslop, Burns, and Lobo (2020) conducted independent studies under different circumstances and revealed more or less similar challenges in teacher mentoring under CPD. Their findings are in line with the findings of this investigation.

The main causes for inadequate performance of DTEs to achieve the targets of the CPD framework are a dearth of expertise, little know-how about science subjects, unrealistic expectations, poor ways of teaching, authoritative behavior, wastage of much time in assessment activities neglecting mentoring, training without needs assessment, and no reward on a good performance, deficiency of poor competence, lack of ownership, non-transferable works and long journeys by DTEs 
to reach the schools. This displays that DTEs are not properly and carefully chosen and are not accurately trained before conveying tasks teachers' mentoring. The mentor may be a veteran, wellinformed, and powerful individual who is engaged to train and coach learners. Swaminathan and Reed (2020) concluded that mentors with administrative behavior were not appreciated by the mentees. These findings are also in partial agreement with our study.

\section{Conclusion}

As per the results of this investigation and the argument, it can be determined that the guiding and mentoring activities of DTEs are unsatisfactory. The majority of practices of the DTEs are at the unsatisfactory (rare level), indicating that mentors are not adequately trained to perform their roles and responsibilities properly. DTEs face several challenges and issues to perform their assigned tasks, as highlighted in the section above, and which need to be substantially addressed.

\section{Recommendations}

Based on the findings and conclusions of the study, it is strongly recommended that the qualifications and competencies of DTEs be urgently assessed and that high-quality training be organized for DTEs before they are sent for field duties at the CTSC level. The key stakeholders in the CPD program (TPSs) should be involved in the planning of CPD activities. The current CPD program needs to be reviewed and all challenges for mentors, mentees, and schools need to be adequately addressed in the revised action plan.

\section{References}

Abdullah, N. G. (2020). Instructing Perceptions, Practices \& their Influences on Relationships during Practicum in Malaysian Primary Schools (Doctoral dissertation, ResearchSpace@ Auckland).

Appel, D. C., Tillinghast, R. C., Winsor, C., \& Mansouri, M. (2020, August). STEM Outreach: A Stakeholder Analysis. In 2020 IEEE Integrated STEM Education Conference (ISEC) (pp. 19). IEEE.

Boukis, A., \& Christodoulides, G. (2020). Investigating key antecedents \& outcomes of employeebased brand equity. European Management Review, 17(1), 41-55.

Cook, C. (2020). Exploring Stakeholders' Perceptions of Juvenile Delinquency Programs in North Carolina: A Qualitative Descriptive Case Study (Doctoral dissertation, University of Phoenix).

Coyne-Foresi, M., \& Nowicki, E. (2020). Building connections \& relationships at school: Youth reflect on instructing their younger peers. The Journal of Early Adolescence, 0272431620912472.

DSD. (2007a). Continuous Professional Development Framework for Primary School Teachers. Directorate of Staff Development, Government of Punjab.

DSD. (2015). Continuous Professional Development Program. Directorate of Staff Development, Government of Punjab.

Galvão, A. R., Marques, C. S., Ferreira, J. J., \& Braga, V. (2020). Stakeholders' role in entrepreneurship education \& training programs with impacts on regional development. Journal of Rural Studies, 74, 169-179.

Heslop, C. W., Burns, S., \& Lobo, R. (2020). Stakeholder perceptions of relationships \& sexuality education, backlash \& health services in a rural town. Sex Education, 20(2), 170-185.

Iqbal, Z.M., Akhlaq, M., \& Chishti, H.S. (2016). Instructing Practices in Pakistan: A Panacea for Professional Development of Primary School Teachers. Journal of Education \& Human Development, 3(5), 97-105.

Milton, E., Daly, C., Langdon, F., Palmer, M., Jones, K., \& Davies, A. J. (2020). Can school provide the learning environment that new teachers need? Complexities \& implications for professional learning in Wales. Professional development in education, 1-14.

Munir, F., \& Amin, M. (2018). Classroom Practices of Mentees \& Mentoring Challenges in the Execution of Continuous Professional Development Framework. Bulletin of Education \& Research, 40(2), 163-178.

Murtagh, L., \& Dawes, L. (2020). National Standards for school-based mentors: the potential to recognize the "Cinderella" role of instructing. International Journal of Instructing \& Coaching in Education. 
Ng, Y. X., Koh, Z. Y. K., Yap, H. W., Tay, K. T., Tan, X. H., Ong, Y. T., ... \& Krishna, L. (2020). Assessing instructing: A scoping review of instructing assessment tools in internal medicine between 1990 \& 2019. PloS one, 15(5), e0232511.

Saeed, M., \& Akhtar, M. (2017). Problems \& issues in the implementation of CPD framework: Perception of district teacher educators \& teacher educators. Pakistan Journal of Educational Research \& Evaluation, 2(1), 1-13.

Saleem, Q. U. A., \& Ashiq, M. (2020). The facts of continuing professional development for LIS professionals in Pakistan: a literature review. The Bottom Line.

Saqib, Z. A., Zhang, Q., Ou, J., Saqib, K. A., Majeed, S., \& Razzaq, A. (2020). Education for sustainable development in Pakistani higher education institutions: An exploratory study of students' \& teachers' perceptions. Int. J. Sustain. High. Educ. 2020

Shanks, R., Attard Tonna, M., Krøjgaard, F., Annette Paaske, K., Robson, D., \& Bjerkholt, E. (2020). A comparative study of instructing for new teachers. Professional development in education, $1-15$.

Shaukat, S., \& Chowdhury, R. (2020). Teacher educators' perceptions of professional standards: Implementation challenges in Pakistan. Issues in Educational Research, 30(3), 1084-1104.

Swaminathan, R., \& Reed, L. (2020). Mentor perspectives on instructing new school leaders. Journal of School Leadership, 30(3), 219-237. 